\title{
Alterations in development of reproductive and endocrine systems of wildlife populations exposed to endocrine-disrupting contaminants*
}

\author{
Louis J. Guillette, Jr and Mark P. Gunderson \\ Department of Zoology, 223 Bartram Hall, University of Florida, Gainesville, FL 32611, USA
}

\begin{abstract}
Wildlife and human populations are affected by contaminants in natural settings. This problem has been a growing concern over the last decade with the realization that various environmental chemicals can alter the development and functioning of endocrine organs, cells and target tissues. Documented disruptions or alterations in reproductive activity, morphology or physiology in wildlife populations have been correlated with contaminantinduced modifications in endocrine system functioning. Alterations of the endocrine system are complex, and not limited to a particular organ or molecular mechanism. For instance, contaminants have been shown to (1) act as hormone receptor agonists or antagonists, (2) alter hormone production at its endocrine source, (3) alter the release of stimulatory or inhibitory hormones from the pituitary or hypothalamus, (4) alter hepatic enzymatic biotransformation of hormones, and (5) alter the concentration or functioning of serum-binding proteins, altering free hormone concentrations in the serum. This review focuses on two of these alterations, altered hormone synthesis and hepatic biotransformation, as a number of recent studies indicate that these actions are important components of endocrine disruption in developing organisms. The possible role of contaminants in altering sex determination mechanisms is also examined.
\end{abstract}

The extent to which embryonic development in wildlife and human populations is affected by contaminants has been a growing concern over the last decade, since the realization that various environmental chemicals can alter endocrine functioning (Guillette and Crain, 2000; McLachlan, 2001). Documented disruptions or alterations in reproductive activity, morphology or physiology in wildlife populations have been correlated with contaminant-induced modifications in endocrine system functioning. Thus, a great deal of the current focus on environmental pollution is on the potential endocrine-altering actions of various chemical contaminants (Knobil et al., 1999; Guillette and Crain, 2000; McLachlan, 2001).

Initial research on wildlife populations exposed to sewage or pesticides demonstrated disrupted endocrine activity and altered reproductive biology after exposure to various classes of contaminant, including pesticides, sewage effluent and pulp mill effluent (for reviews, see Van der Kraak, 1998; Guillette and Crain, 2000). Studies examining public health concerns associated with the endocrine disruptive effects of environmental contaminants have often used human embryonic exposure to diethylstiboestrol (DES)

Email: ljg@zoology.ufl.edu

*This article is based on a presentation given at the British Society of Animal Science symposium 'Early Regulation of Mammalian Development' held in Aberdeen in September 2000. as a model (Knobil et al., 1999; McLachlan, 2001). Concern about endocrine disruption has increased because of the historical use of DES and current use of other hormones in the animal sciences industry (see McLachlan, 2001). This concern has been extended to chemicals released from many industrial activities, sewage treatment works, domestic activities and animal feedlots (for examples, see Blount et al., 2000; Gray et al., 2001). The developmental effects of exposure to environmental contaminants that have the potential to alter endocrine activity in adult animals, including humans, are of particular interest and have been reviewed in detail (for example, see Knobil et al., 1999; Naz, 1999; Guillette and Crain, 2000; McLachlan, 2001).

Several synthetic chemicals as well as some naturally occurring plant compounds have been shown to mimic naturally occurring hormones, to act as anti-hormones or to alter the enzymes responsible for hormone synthesis and degradation (Fig. 1) and have been defined as endocrinedisrupting contaminants (EDCs). Endocrine disruption can occur via multiple mechanisms in adults as well as in developing embryos. Alterations of the endocrine system can be complex, and not necessarily limited to a particular organ or molecular mechanism. For instance, contaminants have been shown to alter: (1) hormone production at its endocrine source; (2) the release of stimulatory or inhibitory hormones from the pituitary or hypothalamus; (3) hepatic 


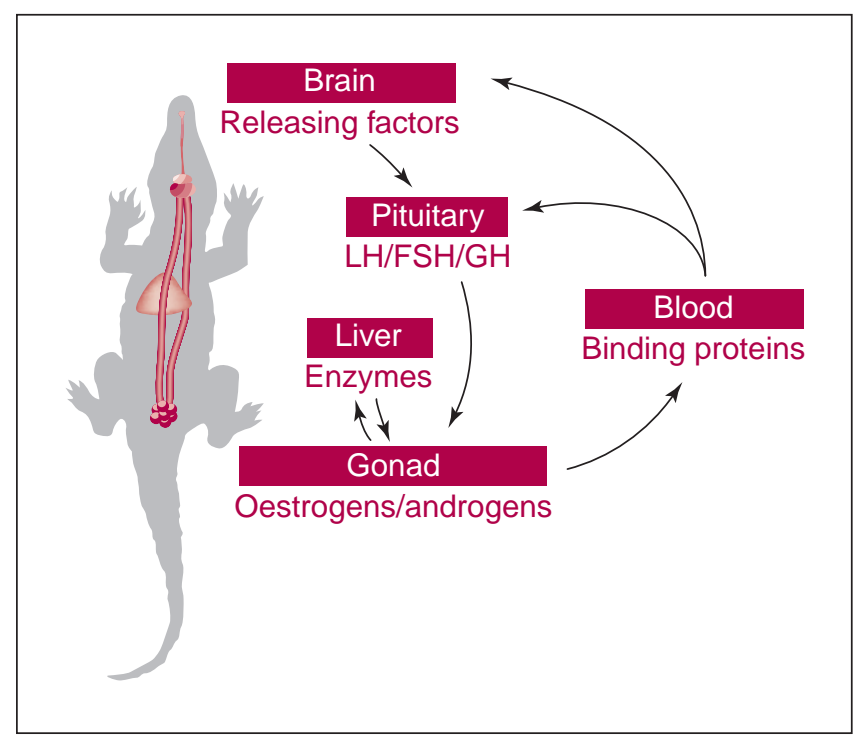

Fig. 1. Endocrine disruption can occur at several sites in the reproductive system: hypothalamo-pituitary function, gonadal hormone synthesis, hepatic biotransformation or serum binding can be altered.

enzymatic biotransformation of hormones; and (4) the concentration or functioning of serum-binding proteins, altering free hormone concentrations in serum (Guillette et al., 2000). All of these mechanisms must be examined if contaminant-induced endocrine disruption is suspected.

Much of the current literature on EDCs has focused on alterations arising from embryonic exposure (Guillette and Crain, 2000). For example, alterations in sex differentiation, modifications of gonadal steroidogenesis, abnormally increased testicular aromatase activity and alterations in hepatic biotransformation of steroids have all been demonstrated after embryonic exposure to EDCs. These findings may be due, in part, to the apparent sensitivity of the developing embryo to chemical signals (Bern, 1992). Radical modification of embryonic structure and function, and thus adult form and function, can be induced by epigenetic influences that produce organizational responses (Guillette et al., 1995). It remains unclear what the longterm effects of these embryonic modifications are on the health and reproductive potential of adults, but they appear to be persistent. Consequently, the influences of such embryonic modifications on populations are difficult to predict and are generally unknown. Current studies of development examine two primary pathways: (1) genetic modifications, such as genetic drift during species isolation or homeosis; and (2) modifications in the timing, presence or amount of chemical signalling. In general, alterations in embryonic development create flexibility in both the form and function of phenotypes and it is this phenotypic variation in body structure and function that allows species to persist and evolve in constantly changing environments. Thus, phenotypic plasticity, a requirement of evolutionary change, provides the framework for possible changes in embryonic form and function resulting from exposure to man-made chemicals. The susceptibility of embryos to phenotypic alteration makes the identification of EDCs and descriptions of their endocrine actions critically important.

\section{Developmental alterations due to embryonic exposure to endocrine-disrupting contaminants}

\section{Alterations in sexual differentiation}

In mammals, steroid hormones have important roles in the development of the internal reproductive ducts and external genitalia. In non-mammalian vertebrates, such as some species of fish, amphibians and reptiles, sex steroids also play a major role in the development of the gonads. For example, in some lizards and turtles and all crocodilians, temperature is a major factor in the determination of gonadal differentiation. In American alligators, incubation temperature during a critical developmental window, midway through development, determines whether it is a testis or ovary that forms (Lang and Andrews, 1994). Pharmaceutical anti-oestrogens and anti-androgens or enzyme blockers (for example, aromatase inhibitors) have been used to show that oestrogens stimulate the formation of an ovary. Given these observations, it is possible that contaminants with agonistic and antagonistic hormonal activity influence the sex determination processes in a wide range of species.

The observations in wild populations are supported by laboratory-based experimental studies demonstrating the ability of various contaminants to alter sexual development in non-mammalian species. Exposure of mosquito fish (Gambusia holbrooki) fry to 4-nonylphenol (50 $\mu \mathrm{g} \mathrm{I}^{-1}$ ) within 3 days of birth resulted in 100\% females on the basis of external morphology, but the sex ratio, on the basis of gonadal sex, was close to $1: 1$ and did not differ from that of controls (Dreze et al., 2000). However, the response to contaminants with endocrine activity varies depending on the species and chemical studied, for example, in studies examining sexual development in salmonids exposed to various environmental contaminants (Carlson et al., 2000).

Ecologically relevant concentrations of some pesticides or their metabolites can induce altered sex determination mechanisms in reptiles with temperature-determined sex. Contaminants reported to alter sex determination (female to male) in alligator or turtle embryos include $o, p^{\prime}$ dichlorodiphenyledichloroethylene (o, $p^{\prime}$-DDE), $p, p^{\prime}$-DDE, $2,3,7,8$-tetrachlorodibenzo- $p$-dioxin (TCDD), indole-3carbinol, trans-nonachlor, $p, p^{\prime}$-dichlorodiphenyledichloroethane $\left(p, p^{\prime}\right.$-DDD) and various hydroxylated polychlorinated biphenyls (PCBs) (Bergeron et al., 1994; Matter et al., 1998; Willingham and Crews, 1999). Competitive binding assays, using partially purified oestrogen receptors from alligator uterus, indicate that $o, p^{\prime}-$ DDE, $p, p^{\prime}-\mathrm{DDE}$, trans-nonachlor, $p, p^{\prime}$-DDD and various PCBs exhibit binding (Vonier et al., 1996). These 
compounds are important in ecological systems as they readily bioaccumulate and biomagnify in the food chain. A commonly bioaccumulated metabolite of the pesticide dichlorodiphenyltrichloroethane (DDT), $p, p^{\prime}-\mathrm{DDE}$, exhibits a variety of actions depending on the species and endpoint examined. $p, p^{\prime}$-DDE has been reported to have oestrogenic activity, no oestrogenic activity and anti-androgenic activity, depending on the species examined (Guillette et al., 2000). Kelce et al. (1995) reported potent antiandrogenic activity, both in vitro and in vivo, for $p, p^{\prime}$-DDE in mammalian systems. Similar studies at the molecular and organism levels have not been performed in other vertebrate species, but data indicate the presence of similar anti-androgenic actions (Gray et al., 2001).

The concentrations of contaminants reported to cause sex reversal in reptiles are within the range of concentrations measured in alligator eggs (Guillette et al., 2000). p, $p^{\prime}-$ DDE, trans-nonachlor, mirex and endrin are present at p.p.b. $\left(\mu g \mathrm{~kg}^{-1}\right)$ concentrations in the serum of juvenile alligators from a contaminated lake, Lake Apopka in Florida (Guillette et al., 1999a). These concentrations are capable of altering sexual differentiation of alligator and turtle embryos (Matter et al., 1998; Willingham and Crews, 1999). In contrast to the DDT metabolites and other compounds, the herbicides atrazine and 2,4-D are not directly oestrogenic (or at least they do not induce male-tofemale sex reversal) in studies in which eggs were exposed to various doses of these chemicals (Guillette et al., 2000). Atrazine, like $p, p^{\prime}$-DDE, exhibits a low affinity for the alligator oestrogen receptor (Vonier et al., 1996). Atrazine, however, applied to the egg shell topically at p.p.m. doses can induce increased testicular expression of aromatase in male alligators (Crain et al., 1997). Studies in a range of species (Gerstenberger et al., 2000; Sanderson et al., 2000) indicate that aromatase activity is a major target of endocrine-disrupting chemicals, as hypothesized by Crain et al. (1997) after their observation of the response in atrazinetreated alligator embryos. 2,4-D does not influence aromatase activity in alligators at the treatment doses used (Crain et al., 1997). It is clear from these studies that contaminants that affect endocrine activity can alter sex determination in a variety of species via a variety of mechanisms.

\section{Alterations in gonadal steroidogenesis}

As reported above, a number of studies have documented altered plasma concentrations of sex steroids in organisms exposed to contaminants with endocrine disruptive activity. Alterations in plasma sex steroids have been reported for fish exposed to pulp mill effluent (Van der Kraak, 1998), sewage effluent (Folmar et al., 1996, 2001) and industrial effluents (Orlando et al., 1999). The mechanisms by which these alterations in plasma hormones occur are not known, but may involve alterations in synthesis, storage or hepatic biotransformation. For example, various pesticides can inhibit the expression of steroidogenic acute regulatory (StAR) protein in Leydig cells in vitro and consequently

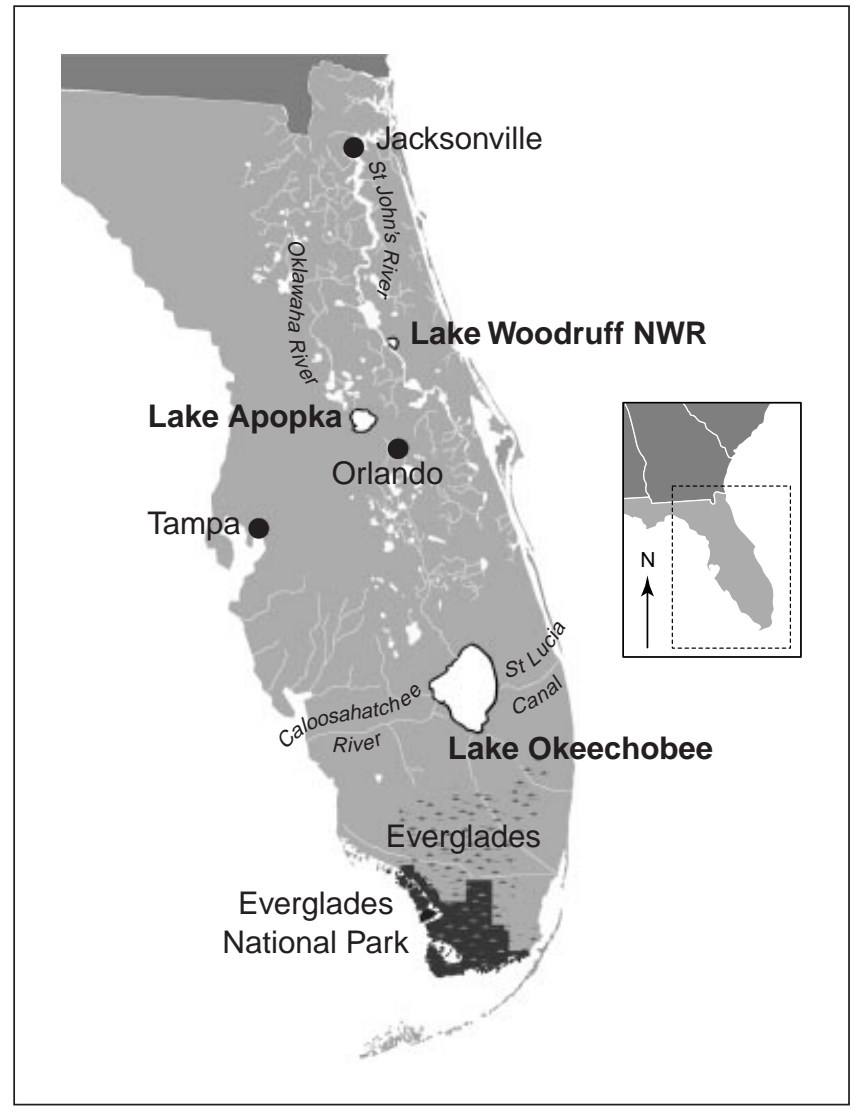

Fig. 2. The endocrine disruptive actions of environmental contaminants have been examined in alligator populations from various sites in Florida, USA, especially lakes Apopka $\left(28^{\circ} 37^{\prime} \mathrm{N}\right.$ $\left.81^{\circ} 37^{\prime} \mathrm{W}\right)$, Woodruff $\left(29^{\circ} 06^{\prime} \mathrm{N} 81^{\circ} 25^{\prime} \mathrm{W}\right)$ and Okeechobee $\left(26^{\circ} 56^{\prime} \mathrm{N} 80^{\circ} 49^{\prime} \mathrm{W}\right)$.

reduce testosterone synthesis (Walsh et al., 2000). This is one of many potential mechanisms that could alter steroidogenesis in the contaminant-exposed gonad.

Skewed sex hormone ratios (E:A) have been observed in alligators exposed to chemicals from normal agricultural activity, municipal runoff and, on one lake, a pesticide spill containing dicofol, DDT and DDE (for a review, see Guillette et al., 2000). Male alligators from a highly contaminated lake, Lake Apopka, in Florida (Fig. 2) had reduced plasma testosterone concentrations that were comparable with female plasma testosterone concentrations and three times lower than those of males from a reference lake, Lake Woodruff. Oestradiol concentrations of juvenile female alligators from Lake Apopka were almost twofold greater than those of females from Lake Woodruff (Guillette et al., 1994). These alterations in plasma sex steroid concentrations are present for years after birth (Fig. 3) and occur in lakes, such as Lake Okeechobee, that do not have a history of pesticide spills like that of Lake Apopka (Crain et al., 1998; Guillette et al., 1999b). The steroidogenic capacity in vitro of gonads taken from juvenile alligators from Lake Apopka and Lake Woodruff have been investigated and it 


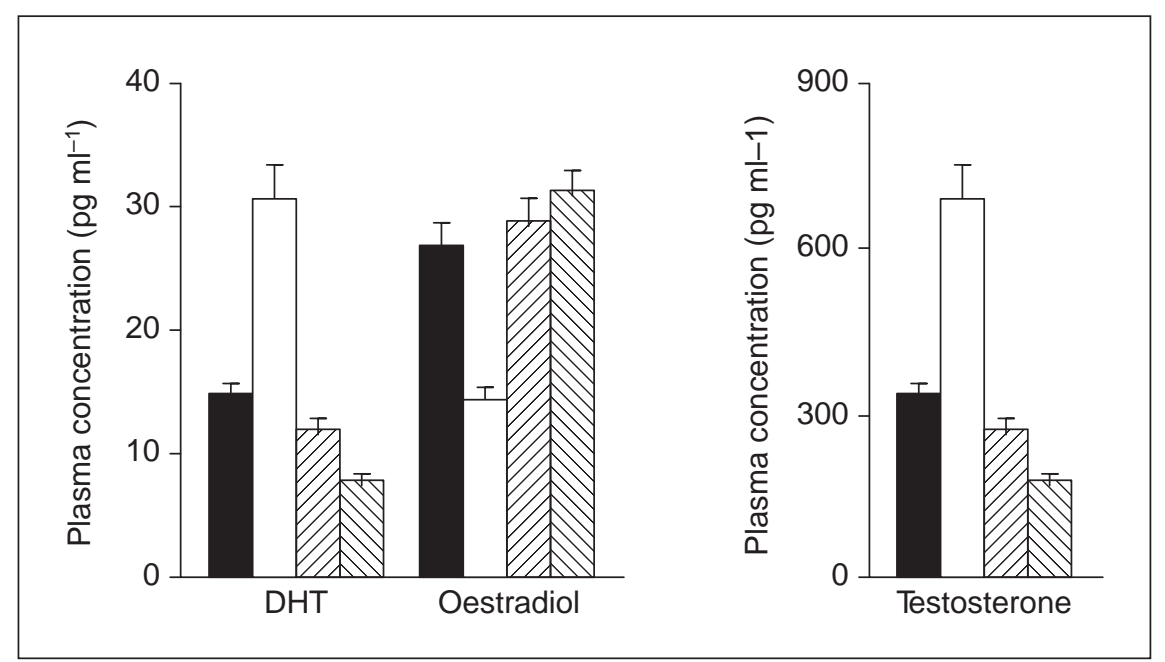

Fig. 3. Juvenile alligators (Alligator mississippiensis) from Lake Apopka, a lake contaminated with pesticides, pesticide metabolites and nutrients, exhibit altered plasma sex steroid concentrations compared with animals from a reference lake, Lake Woodruff. ( Males from Lake Apopka; $(\square)$ males from Lake Woodruff; ( $\square$ ) females from Lake Apopka;

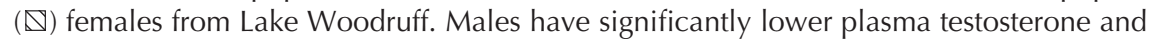
DHT concentrations and higher plasma oestradiol concentrations than reference males. Females exhibit high plasma DHT concentrations compared with reference females. (Data from Guillette et al., 1999b, Pickford et al., 2000.)

has been found that the pattern of steroidogenic activity of the gonads did not match the circulating plasma sex steroid concentrations observed in the same individuals. Circulating plasma oestradiol in vivo was greater in female alligators from Lake Apopka compared with that in controls but oestradiol ovarian synthesis in vitro was lower than normal. The testes of male alligators from Lake Apopka produced more oestradiol in vitro than did testes from males from Lake Woodruff. However, a similar rate of synthesis of testosterone was observed, which was in contrast to the circulating plasma concentrations. On the basis of these observations, it was hypothesized that the differences in sex steroid concentrations observed in vivo and in vitro could be due, in part, to modifications in hepatic biotransformation.

\section{Alteration in hepatic biotransformation of steroids}

\section{Steroid hormone profiles and the liver}

The liver plays an important role in maintaining homeostasis in all vertebrates. In addition to metabolizing toxins, the liver plays a key role in hormone homeostasis, as it metabolizes both peptide and steroid hormones. Hepatic metabolism of many steroids and toxins can occur in a sexually dimorphic pattern and thus can serve as a biomarker for exposure to both naturally occurring and synthetic hormones (see below). The control of steroid hormone profiles involves several variables, including rate of hormone synthesis, interactions among hormones, and rates of secretion, transport, biotransformation and elimination. One route through which normal control could be disrupted is xenobiotic induction of sex steroid metabolizing cytochrome P-450 enzymes. Inducing or blocking these enzymes conceivably alters the natural balance of circulating sex steroids. Several mechanisms are used for hormone biotransformation in the liver. Direct conjugation, in which the steroid is conjugated to glucuronic acid or sulphate, produces a more water-soluble product that can then be excreted in urine (de Bethizy and Hayes, 1994). Steroid hydroxylation accomplishes the same goal by stereo-selectively and regio-specifically attaching hydroxyl groups to a steroid (Wilson et al., 1998). Oxidoreduction of testosterone to androstenedione, dihydrotestosterone and androstanediols is another hepatic biotransformation pathway that influences circulating concentrations of testosterone and other androgens.

\section{Sexual dimorphism and androgen imprinting}

Sexually dimorphic expression of sex steroid metabolizing enzymes has been well documented. Gustaffson (1994) summarized findings on sexual dimorphism of enzyme profiles in liver and reported that, in rats, there is considerable hepatic sexual dimorphism that could be linked to the pulsatile secretions of growth hormone from the pituitary gland under feedback control from oestrogens and testosterone. A hypothalamo-pituitary-hepatic axis that controls liver enzyme activity in a sexually dimorphic manner under the influence of oestrogens and testosterone has been proposed. It is thought that neither the amplitude nor frequency of the growth hormone pulses is recognized 
as male or female but rather it is the prolonged suppression of the $\mathrm{GH}$ pulse in males and the persistence of circulating concentrations of $\mathrm{GH}$ in females that stimulate the sexually dimorphic pattern. Sex-specific forms of hepatic cytochrome $\mathrm{P}-450$ in rats have been reported by Chao and Chung (1982) and Waxman et al. (1985). Chao and Chung (1982) demonstrated that sexual differences in hepatic microsomal drug and steroid metabolism in adult rats are imprinted by androgenic steroids during the neonatal period. Androgen imprinting, as defined by Gustafsson (1994), is neonatal androgen exposure that influences hepatic enzyme responsiveness to androgens in adult life. Cytochrome P-450 from rats imprinted neonatally expresses imprintable testosterone 16 $\alpha$-hydroxylase activity (Chao and Chung, 1982). In contrast, testosterone $7 \alpha$-hydroxylase, $6 \beta$-hydroxylase and benzphetamine $N$-demethylase activity did not show a relationship between imprintability and neonatal androgen exposure (Chao and Chung, 1982). The enzyme $15 \beta$-hydroxylase, found primarily in female rodents, provides a good example of the masculinizing influence of testosterone. Treatment of a female rat with testosterone propionate decreases $15 \beta$-hydroxlase activity (Gustafsson, 1994). However, if a male rat is treated with oestrogen, would the reverse be true? Would 15 $\beta$ hydroxylase be induced? Would a xeno-oestrogen produce a similar effect? Neonatal castration of male rats resulted in complete feminization (that is, an increase) of $15 \beta$-hydroxylase concentrations. This effect was inhibited by administering testosterone propionate on the day after neonatal castration. This finding supports the contention that androgen has a role in masculinizing the rat liver. Administration of oestradiol benzoate to postpubertally castrated male rats (that is, rats with livers imprinted as male) led to transient $15 \beta$-hydroxylase activity (that is, feminization) (Gustafsson, 1994). These examples demonstrate that: (1) androgens and oestrogens influence steroid metabolizing hepatic enzymes; and (2) there is a degree of specificity in neonatal imprinting of particular steroid metabolizing cytochrome P-450 enzymes in rats that could be susceptible to alterations through neonatal exposure to endocrine-active compounds such as anti-androgenic $p, p^{\prime}$ DDE or oestrogenic $o, p^{\prime}$-DDT. This induction-alteration of specific steroid-metabolizing enzymes by xenobiotics might then disrupt hormone homeostasis in the circulating plasma by altering the inactivation, and ultimately the removal, of hormones from the circulation.

\section{Xenobiotics and hepatic biotransformation of hormones}

Baldwin and LeBlanc (1994) demonstrated that xenobiotic exposure was correlated with altered accumulation of exogenously administered steroid hormone and toxicity to steroid-dependent processes in an invertebrate model, Daphnia magna. In mice, endosulfan, a common organochlorine pesticide in widespread use today, caused an increase in total testosterone hydroxyl metabolite formation in females and increased the rate of $16 \beta-, 6 \alpha$ - and
16 $\alpha$-hydroxytestosterone metabolite production (Wilson et al., 1999). However, a coincident decrease in circulating serum hormone concentrations was not demonstrated and Wilson et al. (1999) suggested that other homeostatic processes were able to compensate for the changes in steroid metabolism induced by exposure to endosulfan. The fungicide ketoconozole lowers serum testosterone concentration, lowers gonadal steroid synthesis, and alters hepatic biotransformation of testosterone in $\mathrm{CD}-1$ mice. The lowered serum testosterone concentrations were shown to be due to altered gonadal synthesis, and hepatic inactivation apparently did not play a significant role (Wilson and LeBlanc, 2000). This finding was of interest to the present authors as altered plasma steroid concentrations were observed in juvenile alligators from Lake Apopka but the differences were not easily explained by altered gonadal steroidogenesis (Guillette et al., 2000). A possible explanation for this observation is that wild animals are exposed to a mixture of compounds that might act at many points in the steroid synthesis-degradation pathway during development and throughout the maturational process (Fig. 1). The ratio of $6 \alpha$-hydroxylase: $15 \alpha$-hydroxylase (masculinized $<$ feminized) has been proposed as a biomarker for the androgen status of an animal because of the influence androgen has on the presence of these enzymes (Wilson et al., 1999). A dose-dependent decrease in serum testosterone coincided with a dose-dependent increase in the $6 \alpha$-hydroxylase: $15 \alpha$-hydroxylase ratio after neonatal exposure to indole-3-carbinol (Wilson et al., 1999). In another study, ketoconozole differentially inhibited $15 \alpha$-hydroxylase activity, leading to the increase in the $6 \alpha$ hydroxylase:15 $\alpha$-hydroxylase ratio (Wilson and LeBlanc, 2000). These studies demonstrate that altered plasma testosterone concentrations can be induced by xenobiotics in a laboratory setting and that a lowered plasma testosterone concentration can be linked either to altered hydroxylase enzyme activity in the liver (which is imprinted during development through oestrogen and androgen exposure) or to altered synthesis taking place in the gonads.

\section{Comparative view of hepatic sexual dimorphism}

Sexual dimorphism in cytochrome P-450 enzymes has not only been observed in rodents. Fish, reptiles, birds and marine mammals are among the other classes examined, although far fewer data have been collected than in rodents. For example, CPP1A1 in Beluga whales (Delphinapterus leucas) is correlated with chlorobiphenyl residues and has proved useful as a biomarker for exposure to chemical inducers, as it has been in other species (White et al., 1994). In Beluga whales, 7-ethoxyresorufin O-deethylase (EROD), pentoxyresorufin O-deethylase (PROD), and aryl hydrocarbon hydroxylase (AHH) activities are sexually dimorphic, that is, higher in males than in females (White et al., 1994). Furthermore, CYP1A1 activity is sexually dimorphic and correlated with EROD, PROD and AHH activities, indicating that CYP1A1 is a key catalyst in these reactions. 
A possible explanation for the apparent CYP1A1 sexual dimorphism is the size and age groups sampled for each sex. The six males (highest CYP1A1) sampled also had the highest body fat loads of non-ortho and mono-ortho PCBs, whereas concentrations of these chemicals in the body fat of the five female and two smaller male whales were lower (White et al., 1994). These findings illustrate an important problem for wildlife toxicologists: that, in sampling populations of wild animals, a researcher has little control over what the animals have been exposed to in the past. This is a major problem for investigations of ecologically relevant problems in which mixtures are always present. Furthermore, it is difficult to establish 'normal' standards for comparison with 'exposed' populations.

A number of comparative studies have been performed in fish. Cytochrome P-450 enzymes in scup (Stenotomus chrysops) and other marine fish apparently exhibit catalytic activity similar to that associated with mammalian cytochromes P-448 activity (Stegeman and Binder, 1978). Stegeman and Woodin (1984) investigated sex differences in hepatic microsomal cytochrome P-450 content in several fish species and reported that male fish with mature gonads exhibited five- to tenfold greater enzyme content than did female fish with mature gonads. Suppression of cytochrome P-450 in female fish with mature gonads also accounted for the differences observed between mature and immature killifish (Fundulus heteroclitus) and flounder (Pseudopleuronectes americanus) of similar sex and size (Stegeman and Binder, 1978). Activity of $6 \beta$ - and $16 \beta$-testosterone hydroxylase was sexually dimorphic, and activity was higher in female killifish and winter flounder. In brook trout (Salvelinus fontinalis), 6 $\beta$-testosterone hydroxylase activity exhibited the opposite pattern to that seen in the marine species, with activity higher in males. In contrast, testosterone $16 \beta$-hydroxylase activity in brook trout was similar to that in marine species, and concentrations were higher in females than in males (Stegeman and Woodin, 1984). Oestradiol can both increase and decrease specific hepatic P-450 forms in flounder but other factors are involved in differentially regulating hepatic enzyme activity (Snowberger Gray et al., 1991). For example, oestradiol suppresses CYP1A1 in reproductively active female flounder and scup (Snowberger Gray et al., 1991). EROD activity per nmol P$450 \mathrm{I}^{-1}$ is sexually dimorphic in both species investigated, although the patterns vary seasonally. In scup, for example, EROD-specific activity was not sexually dimorphic in May, was significantly greater in males in June, and was increased in both sexes in September (Snowberger Gray et al., 1991). Snowberger Gray et al. (1991) hypothesize that the apparent seasonal change may be due to migrations to and from more contaminated sites. However, these alterations may also be due to seasonal hormonal changes or changes in diet.

A few studies have investigated the sexual dimorphism of hepatic enzyme profiles in reptiles. Reptiles contain the normal mixed function oxidase system, although alligators (among other reptiles) exhibit a lower and different response to classic inducers than is observed in mammals (Ertl and Winston, 1998). No sexual dimorphism in CYP1A-EROD activity was observed in turtles (Chrysemys picta) from Cape Cod (MA), although sex differences were observed in the seasonal changes in activity. Males from the non-impacted site demonstrated peak activities in May, whereas females from the same site demonstrated peak activity in August (Rie et al., 2000). A different pattern was observed in turtles collected from an impacted site where both males and females demonstrated peak activity in June (Rie et al., 2000).

Avian hepatic imprinting by oestrogens and androgens has yet to be studied, although sexual dimorphism has been demonstrated. Great blue herons (Ardea herodias) exposed to TCDD were able to hydroxylate testosterone at the $2 \beta$, $6 \beta, 15 \alpha, 16 \alpha$ and $16 \beta$ sites. The activities of these hydroxylase enzymes were influenced by age and sex, and $2 \beta$ testosterone hydroxylase and $15 \alpha$-testosterone hydroxylase were specifically induced in adult female herons, $15 \alpha$ testosterone hydroxylase was induced in adult male herons, and $6 \beta$-testosterone hydroxylase was induced in adult females and hatchlings (Sanderson et al., 1997). When great blue herons were compared with chickens, in which $6 \beta$ testosterone hydroxylase, $16 \alpha$-testosterone hydroxylase and $2 \alpha$-testosterone hydroxylase are found (Pampori and Shapiro, 1993), differences in specific concentrations were observed but the same patterns of sexual dimorphism exist (lower in females and higher in males), with the exception of $2 \alpha$-testosterone hydroxylase, which was detected in chickens but was not found in great blue herons.

\section{Endocrine disruption and hepatic biotransformation in alligators}

Altered hepatic biotransformation of testosterone provides a plausible explanation for the differences observed in plasma concentration of steroids in juvenile alligators in Florida (Guillette et al., 2000). Given the fact that the hypothalamus-pituitary axis functions in a sexually dimorphic manner and is imprinted by steroids during development in rodents (Gustafsson, 1994), it is a logical suggestion that this system is susceptible to xenobiotic EDCs. DDT, an organochlorine compound present in the 1980 spill on Lake Apopka, modulates sexual dimorphism by affecting regulatory sites of hepatic metabolism through preferential induction of cytochrome P-450 enzymes in Wistar rats (Sierra-Santoyo et al., 2000). Alligators in other lakes in Florida also have altered circulating plasma testosterone concentrations (Crain et al., 1998; Guillette et al., 1999b). Sexual dimorphisms in hepatic enzyme activity are present in juvenile alligators collected from a reference site (Gunderson et al., in press). Alligators from Lake Woodruff (a reference site) exhibited sexually dimorphic patterns of total testosterone hydroxylase activity, and activity of testosterone hydroxylase was higher in females than in males. This pattern was not observed in juvenile alligators collected from Lake Apopka and was reversed in animals collected from a contaminated site located on the 
south shore of Lake Okeechobee (Gunderson et al., in press). Furthermore, alterations in oxido-reductase and glucuronosyltransferase activities are evident in alligators collected from contaminated lakes when compared with alligators from Lake Woodruff (Gunderson et al., in press). As discussed above, sexual dimorphism, seasonal variation, contaminant body burden, current contaminant exposure and age must all be taken into account when using hepatic enzyme activity as a biomarker for xenobiotic exposure as well as a mechanism to explain altered steroid concentraions in the plasma. Altered hepatic biotransformation may play a role in the observed differences in alligators in contaminated lakes in Florida, although more work is needed to examine other points in the pathways in which plasma steroid concentrations are regulated.

\section{Conclusions}

Environmental contaminants have the potential to alter the development of the reproductive system and liver. Future studies need to examine the endocrine-disruptive actions of contaminants on the hypothalamo-pituitary axis of various wildlife species, as well as the binding proteins that transport these hormones. It is now clear that endocrine disruption is a definite mechanism by which various systems of the developing vertebrate embryo can be altered by exposure to contaminants. Our studies demonstrate that exposed embryos show alterations (both stimulatory and inhibitory) of several systems. The fact that numerous systems can be affected, coupled with the complex milieu of chemicals in the environment, indicate that a great deal of interdisciplinary research is needed to understand the long-term implications of endocrine disruption for populations of wildlife species.

\section{References}

Key references are identified by asterisks.

Baldwin WS and Leblanc GA (1994) Identification of multiple steroid hydroxylases in Daphnia magna and their modulation by xenobiotics Environmental Toxicology and Chemistry 13 1013-1021

Batty J and Lim R (1999) Morphological and reproductive characteristics of male mosquitofish (Gambusia affinis holbrooki) inhabiting sewagecontaminated waters in New South Wales, Australia Archives of Environmental Contamination and Toxicology 36 301-307

Bergeron JM, Crews D and McLachlan JA (1994) PCBs as environmental estrogens: turtle sex determination as a biomarker of environmental contamination Environmental Health Perspectives 102 780-781

*Bern H (1992) The fragile fetus. In Chemically-induced Alterations in Sexual and Functional Development: The Wildlife/Human Connection pp 9-15 Eds T Colborn and C Clement. Princeton Scientific, Princeton

Blount BC, Silva MJ, Caudill SP, Needham LL, Pirkle JL, Sampson EJ, Lucier GW, Jackson RJ and Brock JW (2000) Levels of seven urinary phthalate metabolites in a human reference population Environmental Health Perspectives 108 979-982

Carlson DB, Curtis LR and Williams DE (2000) Salmonid sexual development is not consistently altered by embryonic exposure to endocrineactive chemicals Environmental Health Perspectives 108 249-255

Chao H and Chung LWK (1982) Neonatal imprinting and hepatic cytochrome P-450: immunochemical evidence for the presence of a sex-dependent and neonatally imprinted form(s) of hepatic cytochrome P-450 Molecular Pharmacology 21 744-752
Crain DA, Guillette LJ, Jr, Rooney AA and Pickford DB (1997) Alteration in steroidogenesis in alligators (Alligator mississippiensis) exposed naturally and experimentally to environmental contaminants Environmental Health Perspectives 105 528-533

Crain DA, Guillette LJ, Jr, Pickford DB, Percival HF and Woodward AR (1998) Sex-steroid and thyroid hormone concentrations in juvenile alligators (Alligator mississippiensis) from contaminated and reference lakes in Florida Environmental Toxicology and Chemistry 17 446-452

Davis WP and Bortone SA (1992) Effects of kraft mill effluent on the sexuality of fishes: an environmental early warning? In Chemicallyinduced Alterations in Sexual and Functional Development: The Wildlife/Human Connection pp 113-127 Eds T Colborn and C Clement. Princeton Scientific, Princeton

de Bethizy JD and Hayes JR (1994) Metabolism: a determinant of toxicity. In Principles and Methods of Toxicology pp 59-100 Ed. AW Hayes. Raven Press, New York

Dreze V, Monad G, Cravedi JP, VBiagianti-Risbourg S and LeGac F (2000) Effects of 4-nonylphenol on sex differentiation and puberty in mosquitofish (Gambusia holbrooki) Ecotoxicology 9 93-103

Ertl RP and Winston GW (1998) The microsomal mixed function oxidase system of amphibians and reptiles: components, activities and induction Comparative Biochemistry and Physiology 121C 85-105

Folmar LC, Denslow ND, Rao V, Chow M, Crain DA, Enblom J, Marcino J and Guillette LJ, Jr (1996) Vitellogenin induction and reduced serum testosterone concentrations in feral male carp (Cyprinus carpio) captured near a major metropolitan sewage treatment plant Environmental Health Perspectives 104 1096-1101

Folmar LC, Denslow ND, Kroll K, Orlando EF, Enblom J, Marcino J, Metcalfe C and Guillette LJ, Jr (2001) Altered serum sex steroids and vitellogenin induction in walleye (Steizostedion vitreum) collected near a metropolitan sewage treatment plant Archives of Environmental Contamination and Toxicology 40 392-398

Gerstenberger SL, Heimler I, Smies R, Hutz RJ, Dasmahapatra AK, Tripoli $V$ and Dellinger JA (2000) Minimal endocrine alterations in rodents after consumption of lake trout (Salvelinus namaycush) Archives of Environmental Contamination and Toxicology 38 371-376

Gray LE, Jr, Ostby J, Furr J, Wolf CJ, Lambright C, Parks L, Veeramachaneni DN, Wilson V, Price M, Hotchkiss A, Orlando EF and Guillette LJ, Jr (2001) Effects of environmental antiandrogens on reproductive development in experimental animals Human Reproduction Update 7 248-264

Guillette LJ, Jr and Crain DA (Eds) (2000) Endocrine Disrupting Contaminants: An Evolutionary Perspective. Francis and Taylor, Inc., Philadelphia

Guillette LJ, Jr, Gross TS, Masson GR, Matter JM, Percival HF and Woodward AR (1994) Developmental abnormalities of the gonad and abnormal sex hormone concentrations in juvenile alligators from contaminated and control lakes in Florida Environmental Health Perspectives 102 680-688

Guillette LJ, Jr, Crain DA, Rooney AA and Pickford DB (1995) Organization versus activation: the role of endocrine-disrupting contaminants (EDCs) during embryonic development in wildlife Environmental Health Perspectives 103 (Supplement 7) 157-164

Guillette LJ, Jr, Brock JW, Rooney AA and Woodward AR (1999a) Serum concentrations of various environmental contaminants and their relationship to sex steroid concentrations in juvenile American alligators Archives of Environmental Contamination and Toxicology 36 447-455

Guillette LJ, Jr, Woodward AR, Crain DA, Pickford DB, Rooney AA and Percival HF (1999b) Plasma steroid concentrations and male phallus size in juvenile alligators from seven Florida lakes General and Comparative Endocrinology 116 356-372

*Guillette LJ, Jr, Crain DA, Gunderson M, Kools S, Milnes MR, Orlando EF, Rooney AA and Woodward AR (2000) Alligators and endocrine disrupting contaminants: a current perspective American Zoologist 40 $438-452$

Gunderson MP, LeBlanc GA and Guillette LJ, Jr Alterations in sexually dimorphic biotransformation of testosterone in juvenile American alligators (Alligator mississippiensis) from contaminated lakes Environmental Health Perspectives (in press)

*Gustafsson J-A (1994) Regulation of sexual dimorphism in the rat liver. In 
The Differences Between the Sexes pp 231-242 Eds RV Short and E Balaban. Cambridge University Press, Cambridge

Jobling S, Nolan M, Tyler CR, Brighty G and Sumpter JP (1998) Widespread sexual disruption in wild fish Environmental Science and Technology 32 2498-2506

Kelce WR, Stone CR, Laws SC, Gray LE, Jr, Kemppainen JA and Wilson EM (1995) Persistent DDT metabolite $p, p^{\prime}-D D E$ is a potent androgen receptor antagonist Nature 375 581-585

Knobil E, Bern HA, Burger J et al. (1999) Hormonally Active Agents in the Environment National Academy Press, Washington DC

Lang JW and Andrews HV (1994) Temperature-dependent sex determination in crocodilians Journal of Experimental Zoology $27028-44$

LeBlanc GA (2000) Steroid hormone-regulated processes in invertebrates and their susceptibility to environmental endocrine disruption. In Environmental Endocrine Disrupters: An Evolutionary Perspective pp 126-154 Eds LJ Guillette, Jr and DA Crain. Taylor and Francis, New York

*McLachlan JA (2001) Environmental signaling: what embryos and evolution teach us about endocrine disrupting chemicals Endocrine Reviews 22 319-341

Matter JM, Crain DA, Sills-McMurry C, Pickford DB, Rainwater TR, Reynolds KD, Rooney AA, Dickerson RL and Guillette LJ, Jr (1998) Effects of endocrine-disrupting contaminants in reptiles: alligators. In Principles and Processes for Evaluating Endocrine Disruption in Wildlife pp 267-289 Eds R Kendall et al. SETAC, Pensacola, FL

Matthiessen P, Allen YT, Allchin CR, Feist SW, Kirby MF, Law RJ, Scott AP, Thain JE and Thomas KV (1998) Oestrogenic endocrine disruption in flounder (Platichthys flesus L) from United Kingdom estuarine and marine waters CEFAS, Lowestoft

Naz RK (Ed.) (1999) Endocrine Disruptors - Effects on Male and Female Reproductive Systems CRC Press, Boca Raton, FL

Orlando EF, Denslow N, Folmar L and Guillette LJ, Jr (1999) Comparison of the reproductive physiology of Largemouth bass, Micropterus salmoides, collected from the Escambia and Blackwater Rivers in Florida Environmental Health Perspectives 107 199-204

Pampori NA and Shapiro BH (1993) Sexual dimorphism in avian hepatic monooxygenases Biochemical Pharmacology 46 885-890

Parks LG, Lambright CS, Orlando EF, Guillette LJ, Jr, Ankley GT and Gray LE, Jr (2001) Masculinization of female mosquitofish in Kraft Mill effluent-contaminated Fenholloway River water is associated with androgen receptor agonist activity Toxicological Sciences 62 257-267

Rie MT, Lendas KA, Woodin BR, Stegeman JJ and Callard IP (2000) Hepatic biotransformation enzymes in a sentinel species, the painted turtle (Chrysemys picta), from Cape Cod, Massachusetts: seasonal-, sex- and location-related differences Biomarkers 5 382-394

Sanderson JT, Janz DM, Bellward GD and Giesy JP (1997) Effects of embryonic and adult exposure to 2,3,7,8-tetrachlorodibenzo-p-dioxin on hepatic microsomal testosterone hydroxylase activities in great blue herons (Ardea herodias) Environmental Toxicology and Chemistry 16 1304-1310
Sanderson JT, Seinen W, Giesy JP and van den Berg M (2000) 2-Chloro-S triazine herbicides induce aromatase (CYP19) activity in H295R human adrenocortical carcinoma cells: a novel mechanism for estrogenicity? Toxicological Sciences 54 121-127

Sierra-Santoyo A, Hernandez M, Albores A and Cebrian ME (2000) Sexdependent regulation of hepatic cytochrome P-450 by DDT Toxicological Sciences $\mathbf{5 4} 81-87$

Snowberger Gray E, Woodin BR and Stegeman JA (1991) Sex differences in hepatic monooxygenases in winter flounder (Pseudopleuonectes americanus) and scup (Stenotomus chrysops) and regulation of P-450 forms of estradiol Journal of Experimental Zoology 259 330-342

Stegeman JJ and Binder RL (1978) High benzo[a]pyrene hydroxylase activity in marine fish (Stenotomus versicolor) Biochemical Pharmacology 28 1686-1688

Stegeman JJ and Woodin BR (1984) Differential regulation of hepatic xenobiotic and steroid metabolism in marine teleost species Marine Environmental Research 14 422-425

Van der Kraak G (1998) Observations of endocrine effects in wildlife with evidence of their causation Pure and Applied Chemistry 70 1785-1794

Vonier PM, Crain DA, McLachlan JA, Guillette LJ, Jr and Arnold SF (1996) Interaction of environmental chemicals with the estrogen and progesterone receptors from the oviduct of the American alligator Environmental Health Perspectives 104 1318-1322

Walsh LP, McCormick C, Martin C and Stocco DM (2000) Roundup inhibits steroidogenesis by disrupting steroidogenic acute regulatory (StAR) protein expression Environmental Health Perspectives 108 769-776

Waxman DJ, Dannan GA and Guengerich FP (1985) Regulation of rat hepatic cytochrome P-450: age-dependent expression, hormonal imprinting, and xenobiotic inducibility of sex-specific isozymes Biochemistry 24 4409-4417

White RD, Hahn ME, Lockhart WL and Stegeman JJ (1994) Catalytic and immunochemical characterization of hepatic microsomal cytochromes P-450 in the Beluga Whale (Delphinapterus leucas) Toxicology and Applied Pharmacology 126 45-57

Willingham E and Crews D (1999) Sex reversal effects of environmentally relevant xenobiotic concentrations on the red-eared slider turtle, a species with temperature-dependent sex determination General and Comparative Endocrinology 113 429-435

Wilson VS and LeBlanc GA (1998) Endosulfan elevates testosterone biotransformation and clearance in CD-1 mice Toxicology and Applied Pharmacology 148 158-168

Wilson VS and LeBlanc GA (2000) The contribution of hepatic inactivation of testosterone to the lowering of serum testosterone levels by ketoconazole Toxicological Sciences 54 128-137

*Wilson VS, McLachlan JB, Falls JG and LeBlanc GA (1999) Alteration in sexually dimorphic testosterone biotransformation profiles as a biomarker of chemically induced androgen disruption in mice Environmental Health Perspectives 107 377-384 